\title{
Common Carotid Artery Thickness in Chronic Kidney Disease
}

\author{
Mila Lubomirova*, Rejina Djerassi, Boris Bogov \\ Hospital Alexandrovska, Clinic of Nephrology, 1 "St. G. Sofiiski" str., Sofia 1431, Bulgaria
}

\author{
Citation: Lubomirova M, Djerassi R, Bogov B \\ Common Carotid Artery Thickness in Chronic \\ Kidney Disease. OA Maced J Med Sci. 2014 \\ $\begin{array}{ll}\text { Jun 2(2):257-260 } & \end{array}$ \\ http://dx.doi.org/10.3889/oamjms.2014.042 \\ Key words: intima-media thickness; \\ Key words: intrasononography; chronic kidney disease; \\ ultrasononography; chronic
cardiovascular risk factors. \\ "Correspondence: Mila Lubomirova, MD, PhD \\ Clinic of Nephrology, University Hospital \\ Alexandrovska", 1 "St.G. Sofiiski"str. 1431 \\ Sofia, Bulgaria. Tel: +35929230229, Fax: \\ +35929230248 . \\ MLjubomirova@yahoo.com \\ Received: 19-Feb-2014; Revised: 24-Mar- \\ 2014; Accepted: 18-Apr-2014; Online first: \\ 16-May-2014 \\ Copyright: () 2014 Lubomirova et al. This is \\ an open access article distributed under the \\ terms of the Creative Commons Attribution \\ License, which permits unrestricted use, \\ distribution, and reproduction in any medium, \\ provided the original author and source are \\ credited. \\ Competing Interests: The authors have \\ declared that no competing interests exist.
}

\begin{abstract}
AIM: Previous studies showed that patients with chronic kidney disease (CKD) $>2$ dergee had increased intima-media thickness (IMT). We evaluate the relationship between IMT and parameters for renal function.

METHODS: 130 subjects were examined - 66 with CKD, 44 without CKD, as well as 20 healthy volunteers. The first group- patients with CKD were with creatinine clearance $(\mathrm{CrCl})$ over $20 \mathrm{ml} / \mathrm{min}$ and below $90 \mathrm{ml} / \mathrm{min}$. The second group included 44 pts. with normal renal function, $\mathrm{CrCl}>90$ $\mathrm{ml} / \mathrm{min}$. All examined patients with and without CKD had hypertension. The two groups were streamed into two subgroups: with and without vascular disease. To evaluate the renal function creatinine clearance was calculated in $\mathrm{ml} / \mathrm{min}$. IMT was measured in both common carotid artery (CCA) using high resolution sonography in all examined subjects.

RESULTS: CCA IMT increased in pts. with CKD and was > 0.75 ( $0.76 \pm 0.14$ v.s contols $0.59 \pm$ $0.10)$ Patients with vascular disease (VD) had higher IMT which increased significant when CKD with GFR $<90 \mathrm{ml} / \mathrm{min}$ was included $(0.77 \pm 0.06 / 0.81 \pm 0.10, \mathrm{p}<0.05)$. Multiple regression analysis proved that renal function deterioration directly affected CCA IMT $\left(R^{2}=0.208, p=0.022\right)$.
\end{abstract}

CONCLUSION: Increased IMT is presented in mild renal dysfunction. CKD -GFR< $90 \mathrm{ml} / \mathrm{min}$ could be an independent vascular risk factor.

\section{Introduction}

Chronic kidney disease (CKD) with GFR $<90$ $\mathrm{ml} / \mathrm{min}$ is defined as a "vasculopathic state"[1]. Cardiovascular risk in patients with CKD with imraired renal function is 10-20 times higher than in that of the general population [2]. Cardiovascular complications are major cause of morbidity and mortality in patients with CKD [1]. The intima-media thickness (IMT) of the common carotid artery (CCA) has proved to be a good marker for both the presence of early atherosclerosis and the degree of atherosclerosis of an individual [36]. Ultrasound measurement of (IMT) gives valuable information about the vessel status [7]. Prospective studies have shown a positive correlation between increased carotid artery IMT and the risk for myocardial infarction, stroke, and cardiovascular mortality [3-5]. Classic risk factors- age gender, hypertension duration and severity, obesity, diabetes, directly affect IMT. In contrast to the general population, for patients with CKD facing high risk of cardiovascular disease there aren't many prospective studies on the assessment of IMT changes as well as on association of these changes with the classic and specific for CKD cardiovascular risk factors (CVRF) [8, 9]. Previous studies showed that patients with CKD with GRF $<90 \mathrm{ml} / \mathrm{min}$ had increased IMT $[8,9]$. There are a few data about how impaired renal function influences carotid vascular structure [6, 10]. We evaluate the relationship between IMT and parameters for renal function deterioration.

\section{Material and Methods}

One hundred thirty (130) subjects were examined -66 with CKD, 44 without CKD, as well as 20 healthy volunteers. The first group- patients with CKD were with creatinine clearance $(\mathrm{CrCl})$ over 20 $\mathrm{ml} / \mathrm{min}$ and below $90 \mathrm{ml} / \mathrm{min}$. The second group included 44 pts. with normal renal function, $\mathrm{CrCl}>90$ $\mathrm{ml} / \mathrm{min}$. All examined patients with and without CKS had hypertension. The mean duration of hypertension was $14.45 \pm 7.29$ years. $20 / 66$ pts had diabetes. 25/44 pts of the group without CKD had diabetes type 2. The two groups were streamed into two subgroups: with and without vascular disease (coronary, 
peripheral vascular or brain vascular). Twenty healthy persons with normal blood pressure $(12 \mathrm{~F} / 8 \mathrm{M}$, mean age $45.8 \pm 5.2, \mathrm{CrCl} 117 \pm 18 \mathrm{ml} / \mathrm{min}$ ) were used as a control group for IMT measurement.

Classical CVRF: duration of arterial hypertension and diabetes, lipid metabolism as well as BMI was given in all patients. The normal BMI was up to 24. To evaluate the renal function in all examined subjects $(n=130)$ creatinine clearance was calculated in $\mathrm{ml} / \mathrm{min}$ according to the Cockcfort -Gault formula in $\mathrm{ml} / \mathrm{min}$. The normal $\mathrm{CrCl}$ was $(>90<160$ $\mathrm{ml} / \mathrm{min}$.)

$$
\mathrm{CrCl}=\frac{(140-\text { age }) \times \mathrm{kg} \times 0.814(\times 0.85 \text { for female })}{\text { Serum creatinine }}
$$

Table 1: Distribution of the patients into groups and

\begin{tabular}{|c|c|c|c|}
\hline Groups & $\begin{array}{l}\mathrm{CKD}(\mathrm{N}=66) \\
26 \mathrm{M} / 40 \mathrm{~F} \\
\text { 32/ } 66 \mathrm{HAD} \mathrm{VD}^{* *}\end{array}$ & $\begin{array}{l}\text { NORMAL } \\
\text { RENAL } \\
\text { FUNCTION } \\
\text { (N=44), } \\
17 M / 27 \mathrm{~F} \\
19 / 44 \mathrm{HAD} \\
\text { VD** } \\
\end{array}$ & $\begin{array}{l}\text { HEALTHY } \\
\text { VOLUNTIERS } \\
(\mathrm{N}=20) \\
12 \mathrm{~F} / 8 \mathrm{M}\end{array}$ \\
\hline \multirow{3}{*}{$\begin{array}{l}\text { Age } \\
\text { Serum creatinin } \\
\mu \mathrm{mol} / \mathrm{l} \\
\mathrm{CrCl}^{*} \mathrm{ml} / \mathrm{min}\end{array}$} & $59.9 \pm 14.14$ & $55.7 \pm 15.2$ & $45.8 \pm 5.2$ \\
\hline & $232 \pm 54.03$ & $98 \pm 15.11$ & $88.7 \pm 6.8$ \\
\hline & $36.98 \pm 10.55$ & $91.11 \pm 19$ & $117 \pm 18$ \\
\hline
\end{tabular}
subgroups.

\section{Intima-media thickness}

IMT for either common carotid artery was measured. A total of 260 IMT were examined. IMT was determined by high resolution ultrasonographyATL Phillips in B-mode regime, using $10 \mathrm{MHz}$ linear transducer as described by Kawagishi and Adaikkappan and Pignoli P [11]. The common carotid arteries were scanned in longitudinal and transversal projection. Each patient had undergone individual optimisation of the depth and gain adjustment. IMT was measured in an anterolatteral position 2 см away from the bifurcation. The given values are the average of three consecutive measurements. Normal value for IMT was considered $<0,65 \mathrm{~mm}$

\section{Statistic methods}

Statistical software programs (SPSS 15.0.1) were used. All data were expressed as mean \pm SD. Statistical comparisons between two groups were made with a two-sample t- test. $\mathrm{P}<0.05$ was considered as statistically significant value. To study the linear relationship between CCA IMT and other variables Pearson's correlation test was used. Multivariate logistic regression analysis was performed to assess the influence of the chronic renal failure on the CCA IMT values.

\section{Results}

Significant differences in the mean values of IMT for right and left carotid artery in all examined groups were not found. This is given in Table 2. Intima-media was thickened in pts with CKD the mean value was over $0.75 \mathrm{~mm}$. The values in the CKD group were significantly higher than those in the healthy controls. In the latter IMT was normal (Table 2).

Table 2: Comparative analysis of IMT between patients with renal failure and healthy volunteers.

\begin{tabular}{lccc}
\hline Group & $\mathrm{CrCl} \mathrm{ml/min}$ & $\begin{array}{c}\text { IMT* OF THE } \\
\text { RIGHT CCA }\end{array}$ & $\begin{array}{c}\text { IMT* OF THE } \\
\text { LEFT CCA }\end{array}$ \\
\hline CKD $(\mathrm{n}=66)$ & $36.98 \pm 10.5$ & $0.76 \pm 0.10 \mathrm{~mm}$ & $0.77 \pm 0.06$ \\
$\begin{array}{l}\text { HEALTHY SUBJECTS } \\
(\mathrm{n}=20)\end{array}$ & $117 \pm 18$ & $0.59 \pm 0.10 \mathrm{~mm}$ & $0.60 \pm 0.12$ \\
$\mathrm{P}$ & $<0.001$ & $<0.001$ & $<0.001$ \\
\hline${ }^{*}$ IMT- intima- media thickness; ${ }^{* *} \mathrm{CCA}-$ common carotid artery. &
\end{tabular}

Intima-media is thickened in patients with $C K D$, its value being significantly higher when VD factor was added, $p<0.05$. Patients with VD without CKD had increased IMT of a value that is comparable to the mean value of IMT in the pts. from the CKD group ( $0.77 \pm 0.06 / 0.76 \pm 0.10, p=N S$ ) (Table 3 ).

Table 3: Mean values of IMT patients with and without CKD with GFR $<90 \mathrm{ml} / \mathrm{min}$ and healthy volunteers.

\begin{tabular}{lcccc}
\hline Group & $\mathrm{CrCl} \mathrm{ml/min}$ & $\begin{array}{l}\text { IMT of the } \\
\text { right CCA }\end{array}$ & $\begin{array}{c}\text { IMT of the left } \\
\text { CCA }\end{array}$ & $p$ \\
\hline CKD $(n=66)$ & $36.98 \pm 10.55$ & $0.76 \pm 0.10$ & $0.77 \pm 0.06$ & n.s \\
$\begin{array}{l}\text { CKD+VD* } \\
(n=32)\end{array}$ & $37.09 \pm 9.55$ & $0.81 \pm 0.10$ & $0.80 \pm 0.06$ & n.s \\
$\begin{array}{l}\text { CKDwithout VD* } \\
(n=34)\end{array}$ & $39.29 \pm 11.78$ & $0.75 \pm 0.10$ & $0.74 \pm 0.06$ & n.s \\
$\begin{array}{l}\text { Without CKD ( } n=44) \\
\begin{array}{l}\text { VD without CKD } \\
(n=19)\end{array}\end{array}$ & $91.11 \pm 19$ & $0.77 \pm 0.1$ & $0.78 \pm 0.06$ & n.s \\
$\begin{array}{l}\text { Without CKD.without VD } \\
(n=25)\end{array}$ & $105 \pm 13.37$ & $0.70 \pm 0.22$ & $0.71 \pm 0.06$ & n.s \\
$\begin{array}{l}\text { Healthy controls } \\
(n=20)\end{array}$ & $117 \pm 18$ & $0.59 \pm 0.10$ & $0.60 \pm 0.12$ & n.s \\
\hline
\end{tabular}

To evaluate how important the study of IMT in the effort to precisely examine the early vessel changes in patients with CRF in predialysis stage, an analysis was carried out to fined the correlation between the IMT and parameters of renal function, age, BMI and the duration of diabetes and hypertension. These results are given in table 4 . A negative moderate correlation of IMT with $\mathrm{CrCl}$ was proved as well as the same degree of positive correlation of IMT with duration of CKD, hypertension, diabetes and age. 
Table 4: Correlation of IMT with renal function, duration of renal disease, hypertension and diabetes, BMI and age.

\begin{tabular}{|c|c|c|c|c|c|c|c|c|}
\hline & PARAMETERS & CREATININE & $\mathrm{CRCL}$ & HYPERTENSION DURATION & DIABETS DURATION & CKD DURATION & BMI & AGE \\
\hline Corr.coef. & IMT - right CCA & 0.095 & -0.303 & 0.394 & 0.343 & 0.324 & 0.032 & 0.351 \\
\hline$p$ & $p$ & 0.488 & 0.003 & 0.023 & 0.045 & 0.006 & 0.814 & 0.062 \\
\hline N & $\mathrm{N}$ & 56 & 56 & 100 & 45 & 56 & 100 & 100 \\
\hline Corr.coef & IMT- left CCA & 0.108 & -0.312 & 0.385 & 0.349 & 0.316 & 0.029 & 0.358 \\
\hline $\mathrm{p}$ & $\mathrm{p}$ & 0.428 & 0.004 & 0.033 & 0.021 & 0.003 & 0.831 & 0.04 \\
\hline $\mathrm{N}$ & $\mathrm{N}$ & 56 & 56 & 100 & 45 & 56 & 100 & 100 \\
\hline
\end{tabular}

The regression analysis carried out proved that there was a relation between IMT and creatinine clearance which can be described by a linear model

$\left(p=0.022, R^{2}=0.208\right)$ with the following parameters:

$$
\text { IMT }=1.546-0.007 \mathrm{CrCl} \text {, }
$$

where IMT is intima-media thickness, and $\mathrm{CrCl}$ is creatinine clearance.

When $\mathrm{CrCl}$ decreases by $1 \mathrm{ml} / \mathrm{min}$, IMT increases by $0.005 \mathrm{~mm}$.

What was most important to define IMT and became the result of regression analysis was: VD presence, LDL and total cholesterol levels and CKD presence. The regression model showed that $\left(R^{2}=\right.$ $0.136, p=0.005)$, an increase of age with 1 year led to an IMT increase with 0.002. VD presence led to an IMT increase with 0.037 .

$$
\text { IMT }=0.635+0.001 \mathrm{Age}+0.057 \mathrm{ChrKI} \text {, }
$$

where IMT is intima-media thickness, age - age, a ChrKI is CRF.

CKD was a factor that had a separate and borderline influence with the intima-media thickness formation. Results were summarized in Table 5.

\begin{tabular}{|c|c|c|c|c|}
\hline & \multicolumn{2}{|c|}{ NONSTANDART COEF. } & \multirow{2}{*}{$\begin{array}{l}\text { STANDART } \\
\text { COEF. } \\
\text { Beta }\end{array}$} & \multirow[t]{2}{*}{$\mathrm{P}$} \\
\hline & B & Std. Error & & \\
\hline \multicolumn{5}{|l|}{ SECOND STEP } \\
\hline Constanta & 0.598 & 0.079 & & $<0.001$ \\
\hline Total cholesterol & 0.050 & 0.027 & 0.7148 & 0.054 \\
\hline LDL cholesterol & -0.018 & 0.016 & -0.239 & 0.286 \\
\hline CKD & 0.013 & 0.031 & 0.057 & 0.675 \\
\hline Diabetes duration & 0.023 & 0.025 & 0.111 & 0.369 \\
\hline Age & 0.001 & 0.001 & 0.172 & 0.200 \\
\hline Hypertension duration & 0.006 & 0.003 & 0.401 & 0.027 \\
\hline $\begin{array}{l}\text { VD } \\
\text { LAST STEP }\end{array}$ & 0.070 & 0.028 & 0.351 & 0.013 \\
\hline Constanta & 0.635 & 0.049 & & $<0.001$ \\
\hline Age & 0.001 & 0.001 & 0.191 & 0.090 \\
\hline Vascular disease & 0.057 & 0.022 & 0.286 & 0.012 \\
\hline Total cholesterol & 0.021 & 0.011 & 0.303 & 0.054 \\
\hline Hypertension duration & 0.005 & 0.002 & 0.353 & 0.041 \\
\hline
\end{tabular}

Table 5: Multiple regression analysis of CCA IMT.

\section{Discussion}

IMT, measured by B-image technology, is a morphological parameter and represents the histological verified intima-media segment of the vascular wall [11]. IMT in the CCA is a marker for the degree of arteriosclerosis [6, 12]. The data from the big multicenter studies VHAS (Verapamil in Hypertension and Atherosclerosis Study) $и$ ELSA
(European Lacidipine Study of Atherosclerosis) showed high frequency of CCA structural changes that had been proved by intima-media thickness measurement $[13,14]$. Our results were found to be similar. In less than $30 \%$ of the pts with CKD IMT was found to be normal. This percentage in pts. with normal renal function was 35 . The number of patient with proven VD in both groups was similar. This can be used to prove that CKD was a factor for vascular damage, proved also by the results from the regression analysis. A great number of epidemiological studies in general population proved the relationship between IMT and age, hypertension and diabetes duration and hyperlipidemia [3, 7]. Such correlation has been proved in our patients with CKD. The lower correlation between IMT and hypertension and diabetes duration in our pts. with CKD can be explained with the high heterogenecity of these factors and good correction of hypertension and diabetes in all examined patients.

A lot of data about the correlation between IMT and renal function have been published [15-17]. Some of them showed that in CKD patients the correction of classic cardiovascular risk factors did not reduce the thickened intima-media but the correction of classic cardiovascular risk factors in patients with normal renal function reduced the thickened intimamedia.. Thus is the thesis confirmed that under the conditions of impaired renal function vascular risk factors traditional and specific for CKD act together. CKD is a complex of vasculopathic factors [18]. Our results confirmed negative a correlation between IMT and renal function assessed by $\mathrm{CrCl}$ as well as a positive relation between IMT and CKD duration. Similar results were published by Leoncini and coauthors. They proved that the mean IMT value in pts. with CRF was $0.79 \mathrm{~mm}$, which was significantly higher than that in the healthy controls $(0.65 \mathrm{~mm})$ with normal renal function. The role of age, hypertension duration as predictors for intima-media thickening was proved by their regression analysis. Along with that the authors pointed out that the risk for carotid atherosclerosis grew with $43 \%$ per each decrease of $\mathrm{CrCl}$ with $10 \mathrm{ml} / \mathrm{min}$ [19]. K.H. Rahn published similar results [8].

VD presence affected intima-media thickness independently. The examined patients with VD had thickened intima- media no matter whether they had or had not CKD. The fact that the IMT became 
significantly higher in the presence of CKD with GFR $<90 \mathrm{ml} / \mathrm{min}$ is one more proof that impaired renal function is a vascular damage factor. Staneva and coauthors examined patients with normal renal function with and without coronary artery disease and came to the conclusion that the patients with coronary artery disease had significantly higher IMT which is connected with the gravity of the ischemic disease [20].

Chronic kidney disease patients with impaired renal function are people of the highest cardiovascular risk that is commensurable with the risk in diabetic patients and those who have suffered from myocardial infarction. In recent years work has been carried on to early identify the cardiovascular risk and the early vessels damage markers in high risk patients. IMT measurement in patients with CKD is a stronglyinformative method for proving early vascular changes and for determining the patients with high cardiovascular risk. It is recommendable for that method to be regularly applied in the everyday practice of the nephrologists.

\section{References}

1. Baigent C, Burbury K, Wheeler D Premature cardiovascular disease in chronic renal failure. Lancet. 2000; 356 (9224): 147152.

2. Excerpts from United States Renal Data System 2002 Annual Data Report. Am J Kidney Dis. 2003; 41(2 Suppl 1): S57-S70.

3. Bots MI, Hoes AW, Koudstaal PJ, Hofman A, Grobbee DE. Common carotid intima-media thickness and risk of stroke and myocardial infarction. Circulation. 1997;96:1432-1437.

4. Hodis HN, MackWJ, Kronman RA et al. The role of carotid arterial intima-media thickness in predicting clinical coronary events. Ann Intern Med.1998; 128:262-269.

5. Hollander M, Hak AE, Koudstaal PJ et al. Comparison between measures of atherosclerosis and the risk of stroke. Stroke. 2003;34 :2367-2373.

6. Frauchinger $\mathrm{B}$, Schmid $\mathrm{HP}$ et al. Comparison of carotid arterial resisitive indeces with intima-media thickness as sonographic markers of atherosclerosis. Stroke. 2001; 32(4): 836-841.

7. $A \mathrm{n} d \circ \mathrm{F}$, et al. Ultrasonic evaluation of common carotid intima-media thickness (IMT)-influence of local plaque on the relationship between IMT and age. J Epidemiol. 2000; (Suppl.1): S10-S17.

8. $\mathrm{R}$ a $\mathrm{h} \mathrm{n} \mathrm{KH}$, et al. Vessel wall alterations in patients with renal failure. Hypertens. Res. 2000; 23 (1): 3-6.

9. $S \mathrm{~h} \circ \mathrm{j} \mathrm{i} \mathrm{T,} \mathrm{et} \mathrm{al.} \mathrm{Advanced} \mathrm{atherosclerosis} \mathrm{in} \mathrm{predialysis}$ patients with chronic renal failure. Kidney Int. 2002; 61 (6): 2187-2192.

10. Okura T, Watanabe S, Miyoshi K et al. Intrarenl and carotid hemodynamics in patients with essential hypertension. Am J Hypertens. 2004; 17(3): 240-244.

11. Pignoli P, Tremoli E, Poli A, Oreste P, Paoletti R. Intimal plus medial thickness of the arterial wall: a direct measurement with ultrasound imaging. Circulation. 1986; 74:1399-1406.

12. Staub D, Meyerhans A, Frauchinger B et al. Comparison of the internal carotid artery resistive index with the common carotid artery intima-media thickness. Stroke. 2006; 37(3):800-805.
13. $\mathrm{Z}$ a $\mathrm{n} \mathrm{ch}$ e t $\mathrm{t} \mathrm{i}$ A, et al. The Verapamil in Hypertension and Atherosclerosis Study (VHAS): results of long-term randomized treatment with either verapamil or chlorthalidone on carotid intima-media thickness. J Hypertens. 1998;16(11), 1667-1676.

14. Z a n c h e t t i A, et al. Risk factors associated with alterations in carotid intima-media thickness in hypertension: baseline data from the European Lacidipine Study on Atherosclerosis. $J$ Hypertens. 1998; 16(7), 949-961.

15. K o n i n g s C, et al. Arterial wall properties in patients with renal failure. Am J Kidney Dis. 2002; 39 (6): 1206-1212.

16. L e s k i n e $n \mathrm{Y}$, et al. Carotid atherosclerosis in chronic renal failure-the central role of increased plaque burden. Atherosclerosis. 2003;171(2): 295-302.

17. $\mathrm{R}$ o s s i $\mathrm{M}$, et al. Ultrasonic tissue characterization of the carotid artery in chronic renal failure patients. Nephron. 2002; 91 (2): 270-275.

18. $\mathrm{F}$ a $\mathrm{t} \mathrm{h} \mathrm{i} \mathrm{R}$, et al. The effect of long-term aggressive lipid lowering on ischemic and atherosclerotic burden in patients with chronic kidney disease. Am J Kidney Dis. 2004; 43(1): 4552.

19. L e o n c i n i G, et al. Mild renal dysfunction and subclinical cardiovascular damage in primary hypertension. Hypertension. 2003;42(1): 14-18.

20. Staneva M, Sajkov I, Gadeva Sv, et al. Intima -media thickness of the common carotid artery in patients with and without ischemic heart disease. Diagnostic and therapeutic ultrasound. 2005;1:42-49 (article in Bulgarian). 